\title{
During Infection of Its Host, the Plant Pathogen Ralstonia solanacearum Naturally Develops a State of Competence and Exchanges Genetic Material
}

\author{
Franck Bertolla, ${ }^{1}$ Åsa Frostegård, ${ }^{2}$ Belen Brito, ${ }^{3}$ Xavier Nesme, ${ }^{1}$ and Pascal Simonet ${ }^{1}$ \\ ${ }^{1}$ Laboratoire d'Ecologie Microbienne du Sol, UMR CNRS 5557, Batiment 741, Université Lyon I, 43 bd du \\ 11 Novembre 1918, F-69622 Villeurbanne Cedex, France; ${ }^{2}$ Department of Microbial Ecology, Lund Uni- \\ versity, Ecology Building, SE-223 62 Lund, Sweden; ${ }^{3}$ Laboratoire de Biologie Moléculaire des Relations \\ Plantes-Microorganismes, INRA/CNRS, 31326 Castanet-Tolosan, France \\ Accepted 22 January 1999.
}

In this work we investigated the ability of the plant pathogen Ralstonia solanacearum to develop a state of competence in planta and to be genetically transformed during the infection process. Tomato plants infected with $R$. solanacearum GMI1000 were inoculated with plasmid DNA. $R$. solanacearum clones expressing the marker gene were selected only during the period of time that bacteria were actively multiplying inside the plant vessels. Moreover, experiments in which $R$. solanacearum strains harboring different marker genes were co-inoculated into the plant demonstrated that infecting bacterial strains exchange genetic information in planta by a mechanism that is likely to be transformation. To our knowledge, these results constitute the first demonstration of soil microorganisms developing a state of competence in planta. The biotechnological implications of this result will be discussed.

Additional keywords: genetic transfer.

Natural transformation is a genetically and environmentally controlled process. Bacteria must be in a metabolically active state and encounter precise nutrient and environmental conditions to develop a competent state that allows them to be transformed (Lorenz and Wackernagel 1992, 1994). In the natural environment, bacteria live mostly under nutrientlimited conditions that may limit the development of competence and the frequency of transformation (Roszak and Colwell 1987). However, there may also be other potential habitats (plants, intestines of insects, worms, and the interior of protozoa) for gene exchange by transformation. Plants infected by high concentrations of phytopathogenic bacteria may favor development of natural competence and transformation by free DNA or during cell-cell contact.

In a recent paper, we investigated the in vitro transformation conditions of the phytopathogenic bacteria Ralstonia solanacearum GMI1000. We demonstrated that this bacterium develops a state of natural competence in vitro after cultiva-

Corresponding author: Franck Bertolla; Telephone: 334724482 89; Fax: 334724312 23; E-mail: bertolla@biomserv.univ-lyon1.fr tion under nutrient limitation conditions during its exponential growth phase, permitting transformation with DNA, and we determined the optimal quantity and length of the homologous DNA regions (Bertolla et al. 1997).

$R$. solanacearum causes a lethal wilting disease in numerous and diverse species of plants (Hayward 1991). The bacteria usually enter through the roots, either at wounds or sites of secondary root emergence, invading host plant xylem cells and spreading throughout the vascular system, causing severe wilting that ultimately leads to plant death (Vasse et al. 1995). The physiological basis of the disease is multifactorial. Biochemical and genetic studies indicate that exopolysaccharides and the secreted plant cell wall-degrading enzymes polygalacturonase and endoglucanase are necessary for full virulence and extensive colonization of the vessels, necrosis, and lysis of plant cells (Roberts et al. 1988; Denny et al. 1990; Cook and Sequeira 1991; Allen et al. 1991, 1997). In addition, hrp (hypersensitive response and pathogenicity) genes, which play a key role in the interactions between plants and bacteria and in the ability to cause disease in host plants, have also been identified in this bacterium (Boucher et al. 1987).

In the present study we determined whether genetic competence detected in vitro could also develop during the infection process in planta. We also selected and constructed $R$. solanacearum strains to ascertain whether genetic exchange between infecting bacterial cells could occur in planta.

The first stage of the present study was to detect natural transformation of $R$. solanacearum GMI1000 with plasmid DNA during infection of tomato plants. Seeds of tomato (Lycopersicon esculentum) cultivar UC82B pKHG3 (Béclin et al. 1993) were sown in potting compost (Ets Grassot, Brignais, France), and seedlings were transferred to $10-\mathrm{cm}$ pots and grown in a greenhouse at $20 \pm 2^{\circ} \mathrm{C}$. After 2 weeks, 20 - to 25-cm-high plantlets were inoculated with a bacterial suspension of strain GMI1000 (Message et al. 1978) according to Prior et al. (1990). Briefly, $500 \mu \mathrm{l}$ of inoculum $\left(10^{7} \mathrm{CFU} \mathrm{ml}^{-1}\right)$ was injected into the stem of each tomato plant. Infected plants were then incubated in a growth chamber at $28 \pm 2{ }^{\circ} \mathrm{C}$ with a light regime consisting of $16 \mathrm{~h}$ of light and $8 \mathrm{~h}$ of darkness at $70 \%$ relative humidity. 
For plasmid DNA inoculations, $100 \mu \mathrm{l}$ of plasmid pKSpopA:: $\Omega$ solution (Arlat et al. 1994; $50 \mu \mathrm{g} \mathrm{ml}^{-1}$ ) was injected into the infected stems $0,1,2$, or 3 days after bacterial inoculation. This plasmid is a pBluescript derivative that transforms in vitro the strain GMI1000. It contains the popA gene from GMI1000, into which the aad gene (Prentki and Krisch 1984) conferring resistance to spectinomycin and streptomycin has been inserted. The popA gene is located on a megaplasmid and belongs to the hrp regulon of $R$. solanacearum. This PopA1 protein has been shown to be secreted via the hrp pathway. Bacterial strains in which this gene is mutated display a wild-type pathogenic phenotype (Arlat et al. 1994).

The plants were left to grow for 24 additional hours before being crushed and homogenized in sterile, distilled water with an Ultra-Turrax T25 homogenizer at 25,000 rpm (Janke and Kunkel, Staufen, Germany). The numbers of recombinant $R$. solanacearum clones were determined by plating dilutions of the plant tissue suspensions on BG medium (Boucher et al. 1985) supplemented with the antibiotics spectinomycin and streptomycin (Spc and Sm: $40 \mu \mathrm{g} \mathrm{ml}^{-1}$ for each).

Before plating on BG medium, the plant tissue suspensions were treated with $0.1 \mathrm{mg} \mathrm{ml}^{-1}$ of DNase I (type IIs; Sigma, Saint Quentin Fallavier, France) for $15 \mathrm{~min}$ at $37^{\circ} \mathrm{C}$ to degrade the injected plasmid DNA and prevent transformation from occurring on the plates. To limit fungal contamination, BG medium was supplemented with the fungicides cycloheximide $\left(200 \mu \mathrm{g} \mathrm{ml}^{-1}\right)$ and benomyl $\left(50 \mu \mathrm{g} \mathrm{ml}^{-1}\right)$. The efficiency of the DNase treatment was evaluated on agarose gels. CCC (covalently closed circular), OC (opened circular), and linear plasmid forms could not be detected after the treatment. Moreover, no PCR (polymerase chain reaction) amplification was obtained when targeting the aad marker gene (data not shown). Each transformation experiment was done at least in triplicate. In parallel, the $R$. solanacearum growth kinetics were determined in tomato plants inoculated and not inoculated with plasmid DNA. After 0, 2, 3, and 5 days, stems were crushed and homogenized as described above, and serial dilutions of the plant tissue suspensions were plated in BG medium.

The population dynamics of the strain GMI1000 in planta showed that $R$. solanacearum multiplied extensively inside plant tissues during infection. The number of CFUs had increased from the inoculum level $\left(2.4 \times 10^{6}\right)$ to $1.1 \times 10^{10} \mathrm{~g}^{-1}$ fresh plant tissue by day 4 (Fig. 1), corresponding to about a $10^{4}$-fold increase in $96 \mathrm{~h}$. A parallel can be drawn between the growth kinetics in planta and in vitro. We determined whether the competence state, which was restricted to the exponential growth phase under in vitro conditions (Bertolla et al. 1997), also developed in planta. Indeed, recombinant clones were only detected 48 and $72 \mathrm{~h}$ after bacterial infection (Fig. 1) at a frequency of $3.3 \times 10^{-7} \pm 1.1 \times 10^{-7}$ and $3 \times 10^{-8} \pm 2.4 \times 10^{-8}$ transformants per viable recipient cell, respectively. The controls were as expected, i.e., no transformants were detected when water was substituted for the plasmid solution. Similarly, no modification of the population dynamics was observed due to plasmid injection. All the recombinant clones showed positive amplification with the primers FGPaad1172 (5'-ATTCCGTGGCGTTAT-3') and FGPaad1554' (5'-TGAC GGGCTGATACT-3') complementary to regions of the aad gene, while there was no amplification of the DNA from the untransformed strains with these primers (Fig. 2). The PCR products had the expected size (382 bp), deduced from sequence data. Moreover, DNA from the recombinant clones and from the parent GMI1000 strain was amplified with primers FGPS5 and FGPS1509' (Normand et al. 1996), complementary to conserved regions of the $16 \mathrm{~S}$ rDNA. The banding patterns of the PCR products, restricted with the enzymes HaeIII, AluI, and HpaII, were identical and confirmed the $R$. solanacearum origin of the Sm- and Spc-resistant clones (data not shown). The background of epiphytic bacteria in uninoculated plants is 3,630 bacteria per gram of fresh matter. We did not detect any transformant in plants in which DNA was injected but which had not been inoculated with $R$. solanacearum.

These results show that the plant provides a niche where microorganisms, in this case $R$. solanacearum, can develop metabolic activities to reach a state of competence that is likely to be repressed, or at least more rare, during life in soil (Lorenz and Wackernagel 1992). Interestingly, the competence state was transient and appeared to be closely related to the active growth phase of the bacteria. Thus, these results are similar to those that we obtained in vitro (Bertolla et al. 1997).

Since $R$. solanacearum has the ability to develop natural competence in planta and to take up and integrate homologous DNA, we hypothesized that genetic material could be transferred between two pathogenic, invading strains during the infection process. Two pathogenic strains of $R$. solanacearum,

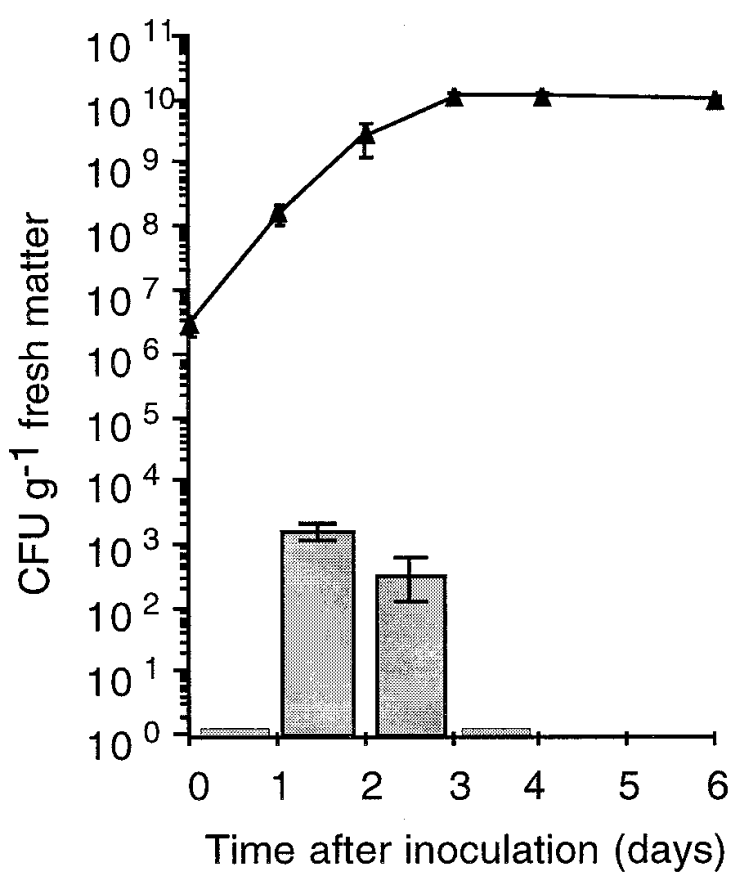

Fig. 1. Detection of a competence state in planta. Infection kinetics were determined as the number of CFU obtained from homogenized plant tissue (described in text). To study development of competence, the infected stems were inoculated after $0,1,2$, or 3 days with $5 \mu \mathrm{g}$ of plasmid pKSpopA:: $\Omega$. After $24 \mathrm{~h}$ of incubation, plants were crushed and homogenized. Plant tissue suspensions were treated with DNase before plating on BG medium (Boucher et al. 1985) supplemented with spectinomycin, streptomycin, cycloheximide, and benomyl. Boxed areas represent number of transformants per gram of fresh matter. Error bars show standard deviations of triplicates. 
GMI1000FAP2 and GMI1581, carrying different antibiotic markers were co-inoculated into tomato plants. Strain GMI1000FAP2 harbors the nptII gene, conferring resistance to the antibiotics kanamycin and neomycin (Km and Neo: 25 $\mu \mathrm{g} \mathrm{ml}^{-1}$ for each), inserted the popA gene of $R$. solanacearum, whereas GMI1581 carries the aad gene $\left(\mathrm{Spc}^{\mathrm{r}}\right.$ and $\left.\mathrm{Sm}^{\mathrm{r}}\right)$ in the HindIII restriction site located in the transcriptional unit 6 of the hrp gene cluster, previously described by Arlat et al. (1992). The popA gene and the transcription unit 6 are approximately $23 \mathrm{~kb}$ distant (Fig. 3).

To generate the recombinant strains GMI1000FAP2 and GMI1581, the parental strain GMI1000 was transformed with plasmids pFAP2 and pBBL1023, respectively. The plasmid pFAP2 was constructed by PCR amplification of the popA gene from the strain GMI1000 with the primers FGPpopA519 and FGPpopA893' (Bertolla et al. 1997), as described by Simonet et al. (1990). However, the Pfu DNA polymerase (Stratagene, Cambridge, UK) was used to avoid single base 3' overhangs and to obtain blunt-end fragments. The resulting 400-bp-long DNA fragment was cloned into the pBluescript vector and digested with SmaI and SpeI, creating the pFAP1 plasmid. For blunting of digested vector, T4 DNA polymerase and Klenow fragment (Boehringer Mannheim France SA, Meylan, France) were used (Maniatis et al. 1982). The pFAP1 plasmid was linearized in the popA region by digestion with
BamHI. The nptII gene was excised from Tn5 (Simon et al. 1983) by digestion with the enzymes HindIII and SalI. Both vector and insert were treated to make them blunt ended (see above) before ligation. The resulting pFAP2 plasmid was transferred to $R$. solanacearum GMI1000 by electroporation according to the protocol described by Burns and Hedin (1991). Presence of the nptII gene in $\mathrm{Km}^{\mathrm{r}}$ transformants was confirmed by PCR with primers complementary to part of the popA gene. The size of the PCR product $(1,590 \mathrm{bp})$ was as expected, confirming the integration of the nptII gene into the popA gene of the recipient strain (data not shown).

To generate plasmid pBBL1023, we ligated the aad gene into the HindIII restriction site of plasmid pBBL102, which carries a 3.3-kb EcoRI/KpnI fragment that encompasses transcription units 5 and 6 of the hrp gene cluster (Brito et al. 1999). pBBL1023 was linearized at the $X b a I$ site and transformed to GMI1000 following the protocol of Boucher et al. (1985). The correct insertion of the aad marker gene was confirmed by Southern blot with total DNA from the recombinant strain hybridized with a 2.3-kb EcoRI/HindIII DNA probe adjacent to the cloning site.

The recombinant strains yielded symptoms in the plants that were similar to those caused by the parental strain, including severe necrosis around the infection sites, and the pith of wilted plants appeared water-soaked, brown, and hollow. To-

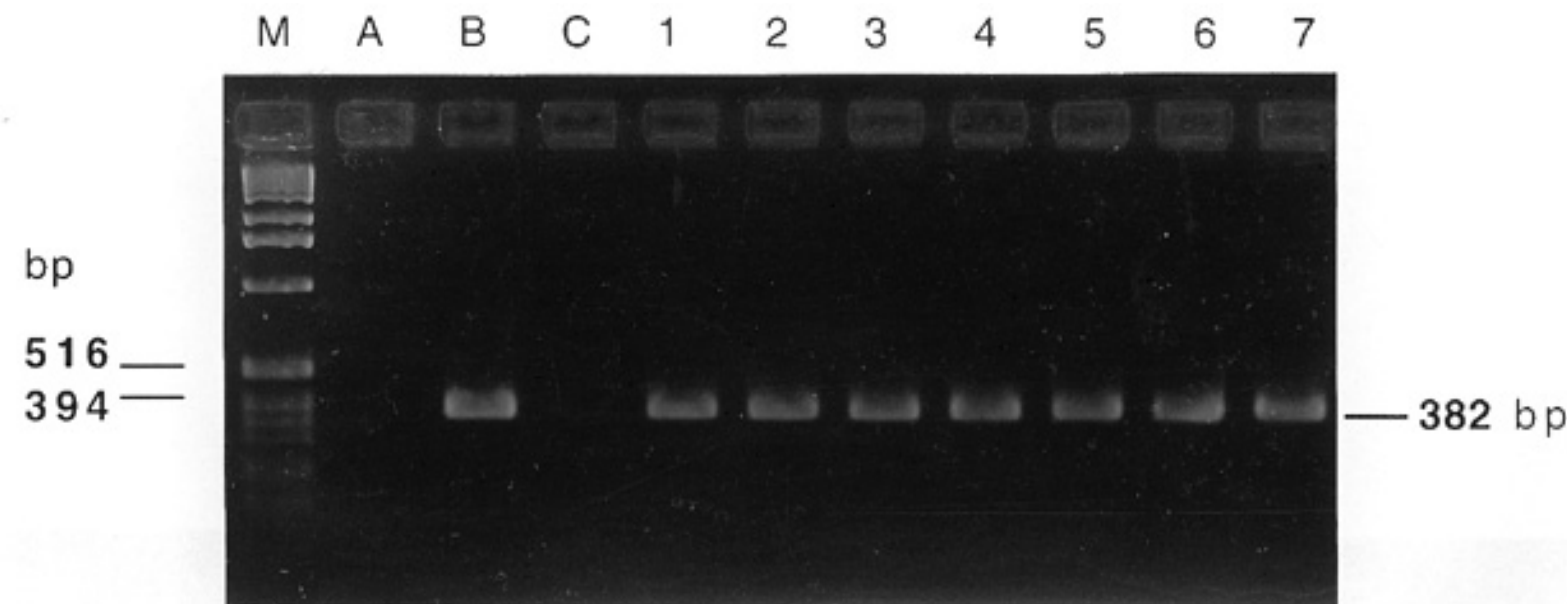

Fig. 2. Verification of presence of the aad marker gene ( $\mathrm{Sm}$ and $\mathrm{Spc}$ ) in the genome of the transformants. The gene was amplified by PCR (polymerase chain reaction) with the primers FGPaad1172 and FGPaad1554'. Amplification consisted of 3 min of initial denaturation at $95^{\circ} \mathrm{C}, 35$ cycles of 1 min of denaturation at $95^{\circ} \mathrm{C}, 1 \mathrm{~min}$ of annealing at $55^{\circ} \mathrm{C}$, and $30 \mathrm{~s}$ of extension at $72^{\circ} \mathrm{C}$. Lane $\mathrm{M}$ contained the $1-\mathrm{kb}$ marker ladder; lane $\mathrm{A}$ contained an $\mathrm{H}_{2} \mathrm{O}$ control; lane B corresponds to PCR products obtained from pKSpopA:: $\Omega$; lane C contained a negative control from genomic DNA of Ralstonia solanacearum GMI1000; and lanes 1 to 7 correspond to PCR products obtained from the genomic DNA of recombinant clones.

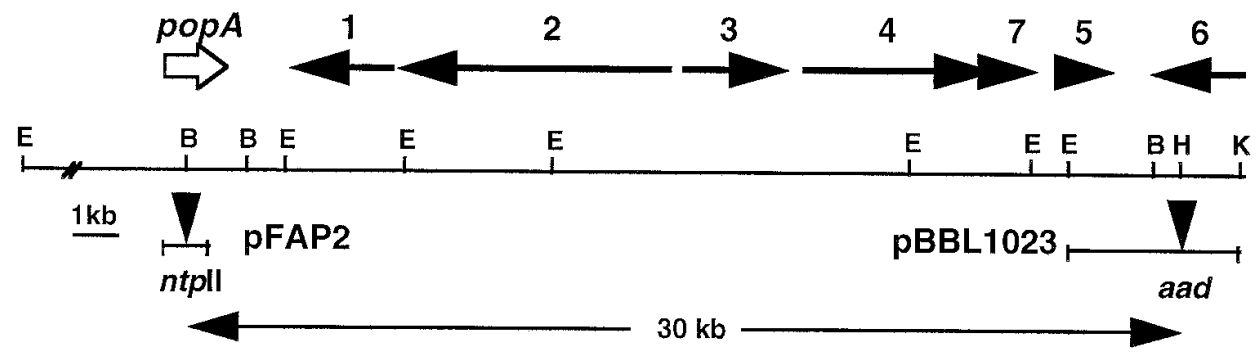

Fig. 3. Scheme of the hrp gene cluster of Ralstonia solanacearum GMI1000. Horizontal arrows indicate hrp transcriptional units. The popA gene is represented by an open arrow. Horizontal lines show $R$. solanacearum DNA regions cloned in plasmid pFAP2 and pBBL1023. Vertical arrowheads indicate position of the nptII and the aad genes in pFAP2 and pBBL1023, respectively. 
mato plants infected with the GMI1581 and GMI1000FAP2 strains wilted within 6 days of the first appearance of symptoms, as occurs with infection by the wild-type GMI1000 strain (results not shown). The population dynamics in planta were similar for strains GMI1581 and GMI1000FAP2. The number of bacterial cells reached densities of $1.05 \times 10^{10}$ and $8.34 \times 10^{9} \mathrm{CFU} \mathrm{\textrm {g } ^ { - 1 }}$ fresh material after 5 days, respectively (Fig. 4A and B). Moreover, no spontaneous $\mathrm{Spc} / \mathrm{Sm}$ or $\mathrm{Km} / \mathrm{Neo}$ mutants were isolated from plants during the infection phase (Fig. 4A and B). Each inoculation experiment was done at least in triplicate.

When the strains GMI1581 $\left(\mathrm{Spc}^{\mathrm{r}}\right.$ and $\left.\mathrm{Sm}^{\mathrm{r}}\right)$ and GMI1000FAP2 $\left(\mathrm{Km}^{\mathrm{r}}\right.$ and $\left.\mathrm{Neo}^{\mathrm{r}}\right)$ were co-inoculated, the number of bacterial cells reached $4.27 \times 10^{9}$ and $3.82 \times 10^{9} \mathrm{CFU}$ $\mathrm{g}^{-1}$ fresh material after 5 days, respectively. Recombinant clones exhibiting resistance to $\mathrm{Spc} / \mathrm{Sm}$ and $\mathrm{Km} / \mathrm{Neo}$ were isolated from tomato plant tissue after 2 days (Fig. 4C). The frequency of recombinant clones per viable recipient cell reached $1.34 \times 10^{-7}$. The possibility for gene transfer occurring after plating of bacteria was tested by plating bacterial suspensions $\left(10^{8}\right.$ bacteria per plate) of both strains together on selective medium containing $\mathrm{Spc} / \mathrm{Sm}$ and $\mathrm{Km} / \mathrm{Neo}$. No transformant was detected, eliminating this hypothesis.

RFLP (restriction fragment length polymorphism) on PCR products of the $16 \mathrm{~S}$ rDNA gene confirmed that the recombinant clones originated from the $R$. solanacearum parental strains (data not shown). The presence of the aad and nptII marker genes in the genome of the recombinants was confirmed by PCR with specific primers FGPaad1172/ FGPaad1554' (see above) and FGPnptII1544 (5'-GTTTCG CA TGATCAAACAAGAT-3')/FGPnptII2347'(5' AACTGCT CGAGAAACTCG-3'). All the recombinant clones yielded a 382-bp-long DNA fragment similar in size to that obtained with the GMI1581 strain (Fig. 5A) and a 803-bp-long DNA fragment similar in size to that obtained with the GMI1000FAP2 strain (Fig. 5B). This confirms that horizontal gene transfer actually occurred in planta. In order to confirm that no aberrant recombination events/rearrangements occurred in the hrp DNA region between the marker genes, the phytopathogenicity of one recombinant clone was studied by inoculation of tomato plants. The number of bacterial cells recovered from infected plant tissue was similar to the number recovered from the parental strains $\left(9.8 \times 10^{9} \mathrm{CFU} \mathrm{g}^{-1}\right.$ fresh material after 5 days), and the recombinant strain produced typical disease symptoms. However, a slight reduction of wilt symptom severity was observed with this clone, perhaps due to additive effects of mutations in the hrp gene cluster.

Our experiments show that $R$. solanacearum develops a competence state in planta that enables it both to take up injected plasmid DNA and to exchange genetic information between bacterial strains. These results provide strong evidence that gene transfer actually occurs during the infection process. However, our co-inoculation data do not allow us to determine whether the transfer was directed preferentially from one strain to the other or whether both strains acted as donor and recipient. On the other hand, horizontal gene transfer between infected bacterial strains is not dependent on the specific genetic marker, since recombinant clones were also detected in co-inoculations with $R$. solanacearum strains carrying other antibiotics (data not shown). Since the bacteria developed competence during infection when active growth

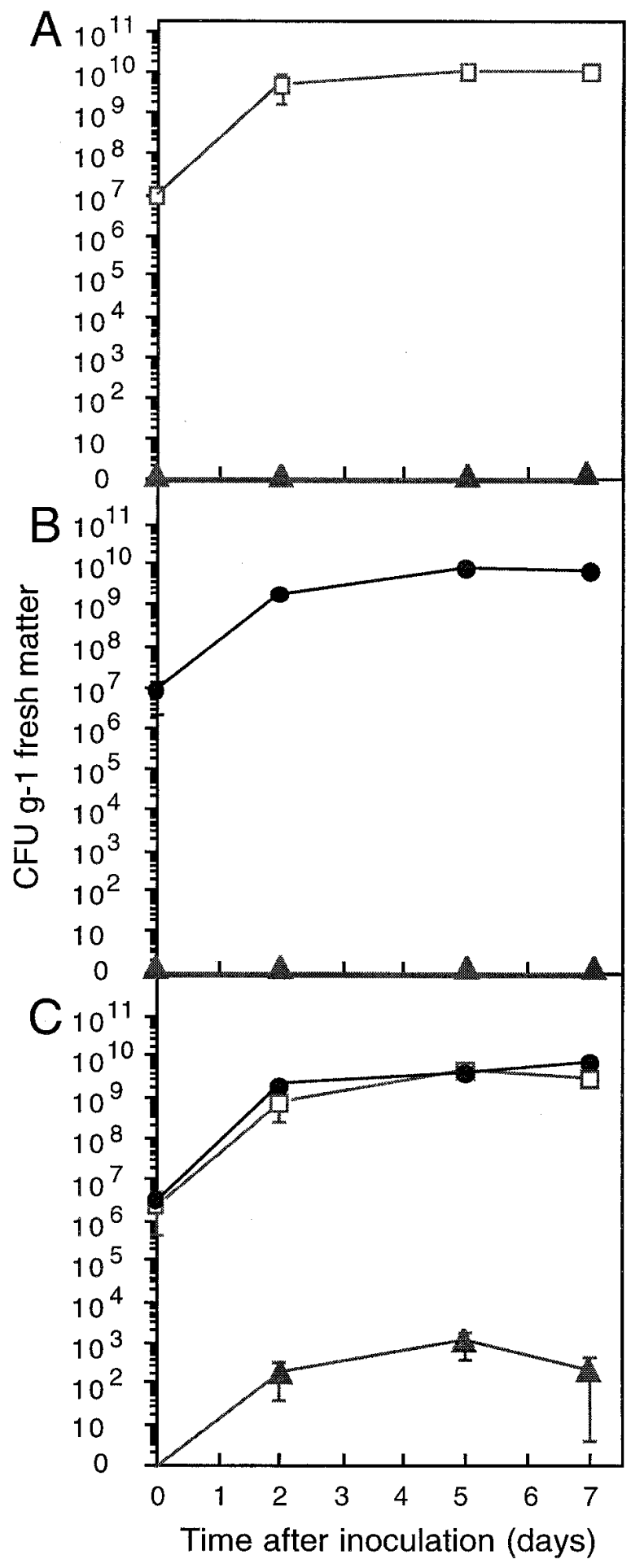

Fig. 4. Detection of exchange of genetic material between infecting bacterial strains. CFUs $\mathrm{g}^{-1}$ fresh matter were determined for the inoculated strains GMI1581 (open squares) and GMI1000FAP2 (solid circles) and for the $\mathrm{Spc} / \mathrm{Sm}$ and $\mathrm{Km} / \mathrm{Neo}$ resistant clones (solid triangles). Error bars show standard deviations of triplicates. Moreover, in some instances, mean value symbols from three replicate experiments obscure the smaller standard error bars. 
occurs, we believe that the mechanism of genetic transfer was transformation. However, conjugation cannot be totally excluded since the marker genes (nptII and aad genes) were located on the megaplasmid (Boucher et al. 1987). To eliminate this hypothesis, DNase treatments were performed in laboratory experiments as described by Paget et al. (1992). Strains GMI1000FAP2 and GMI1581 were mixed and transformed on plates by the method of Bertolla et al. (1997). No transformants were detected when the cells were treated by DNase, whereas transformants were obtained at $2.3 \times 10^{-8}$ frequency with the untreated control transformation. The degradation of the donor DNA by DNase indicates that horizontal gene transfer was due to a transformation process. Thus, it can be hypothesized that bacterial cells, lysed during the infection process, will provide sufficient amounts of donor DNA to allow competent cells to be efficiently transformed.

That plants provide an ecological niche where specific organisms can exchange genetic information was suggested in earlier work. For example, Manceau et al. (1986) demonstrated the transfer of RP4 plasmid between Xanthomonas campestris pv. corylina and Erwinia herbicola in hazelnut tissues, in planta. In $R$. solanacearum, the uptake of foreign DNA during the infection process provides the possibility for bacteria to increase their genetic variability, which would enhance their capacity to adapt to adverse conditions, or to overcome plant resistance mechanisms. The mechanism of natural transformation allows exchanges of sequences in the genome of the bacterium by recombination. These recombinations localized on precise loci could modify the structure of the population of $R$. solanacearum in host plants and prevent the development of a clonal population structure, but only if the frequency of such recombination affecting a single gene is high compared with the rate of mutation of that gene (Maynard Smith et al. 1991). The natural transformation favors a mosaic structure of different loci, thus modifying the structure of the population to an epidemic structure that would be favorable to the emergence of new pathogens (Maynard Smith et al. 1993). It can be speculated that genetic transfer via a transformation mechanism might be a strategy evolved by the plant pathogen $R$. solanacearum, enabling it to invade its host more efficiently or to increase its host range. This could explain why Eucalyptus spp., previously resistant to $R$. solanacearum, were recently found to be susceptible to some pathogenic strains of this bacterium (Hayward and Hartman 1994). Interestingly, gene transfer detected in this study was localized in DNA sequences near to the hrp gene cluster that is involved in bacterial virulence.

Sequence similarity studies have indicated that DNA transfer from plants to bacteria might have occurred over evolutionary time (Smith et al. 1992). The most probable mechanism in promoting such DNA transfer is natural transformation of bacteria with naked DNA released by plant cells. Moreover, it has been hypothesized that symbiosis or parasitism between plants and prokaryotes, in which infecting bacteria are metabolically active and develop in plant tissue in close contact with nuclear material, may provide the most conducive conditions for this genetic transfer (Schlüter et al. 1995). In recent years, the use of bacterial antibiotic resistance genes in the production of transgenic plants has generated much controversy. The reason is the potential risk of dissemination of these genes in bacterial populations due to a higher probability of gene transfer from plants to bacteria in the pres-

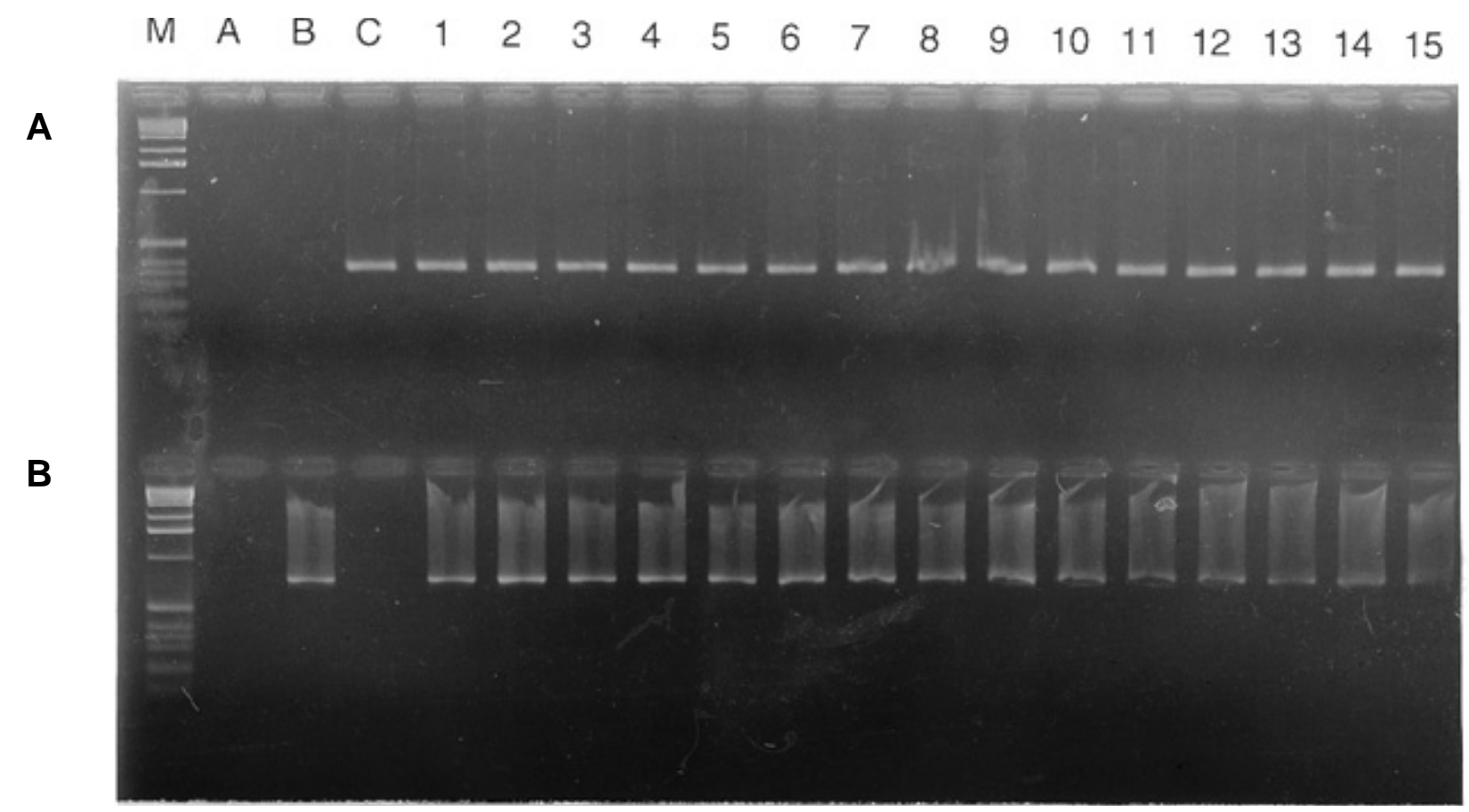

Fig. 5. Verification of the presence of the aad marker gene $(\mathrm{Sm} / \mathrm{Spc})$ and the $n p t I I$ marker gene $(\mathrm{Km} / \mathrm{Neo})$ in the genome of the recombinants. A, The aad gene was detected by PCR (polymerase chain reaction) with both primers FGPaad1172 and FGPaad1554' (see Figure 2). B, The $n p t I I$ gene was detected by PCR with both primers FGPnptII1544 and FGPnptII2347'. Amplifications were done for 35 cycles. Starting with initial denaturation for 3 min at $95^{\circ} \mathrm{C}$, the following denaturation cycles consisted of $1 \mathrm{~min}$ at $95^{\circ} \mathrm{C}, 1 \mathrm{~min}$ at $52^{\circ} \mathrm{C}$, and $30 \mathrm{~s}$ at $72^{\circ} \mathrm{C}$. Lane $\mathrm{M}$ contained the $1-\mathrm{kb}$ marker ladder; lane A is an $\mathrm{H}_{2} \mathrm{O}$ control; lane B and C correspond, respectively, to PCR products obtained from strains GMI1000FAP2 and GMI1581; and lanes 1 to 5, 6 to 10 , and 11 to 15 correspond to PCR products obtained from genomic DNA of recombinant clones at 2, 5, and 7 days, respectively. 
ence of homologous sequences. Recently, the soil bacterium Acinetobacter sp. strain BD413 was shown to be able to take up and incorporate DNA from genes inserted in transgenic plants in vitro (Gebhard and Smalla 1998). Moreover, Schlüter et al. (1995) have investigated the possible transformation of the potato pathogen Erwinia chrysanthemi inoculated in transgenic potato tubers. No evidence of transfer of genetic information from transgenic potato to microorganisms has been described. However, development of a competence state in planta of $R$. solanacearum can be a favorable factor for horizontal gene transfer between $R$. solanacearum and transgenic plants containing homologous sequences. Thus, dissemination of transgenes in $R$. solanacearum population cannot be completely excluded and this potential risk will be estimated in future studies.

\section{ACKNOWLEDGMENTS}

We are very grateful to Stephane Peyrard and Sophie Thomas for technical assistance and Matthieu Arlat for helpful suggestions and critical reading of the manuscript. Financial support from the "Biotechnologie" program of the "Ministère de l'Education Nationale, de la Recherche et de la Technologie," from MENRT (F. B.), the Swedish Council for Forestry and Agricultural Research (A. F.), and the European Commission TMR Marie Curie program (B. B.), is gratefully acknowledged.

\section{LITERATURE CITED}

Allen, C., Gay, J., and Simon-Buela, L. 1997. A regulatory locus, pehSR, controls polygalacturonase production and other virulence functions in Ralstonia solanacearum. Mol. Plant-Microbe Interact. 10:1054-1064.

Allen, C., Huang, Y., and Sequeira, L. 1991. Cloning of genes affecting polygalacturonase production in Pseudomonas solanacearum. Mol. Plant-Microbe Interact. 4:147-154.

Arlat, M., Gough, C. L., Zischek, C., Barberis, P. A., Trigalet, A., and Boucher, C. A. 1992. Transcriptional organization and expression of the large hrp gene cluster of Pseudomonas solanacearum. Mol. PlantMicrobe Interact. 5:187-193.

Arlat, M., Van Gijsegem, F., Huet, J. C., Pernollet, J. C., and Boucher, C. A. 1994. PopA1, a protein which induces a hypersensitivity-like response on specific Petunia genotypes, is secreted via the Hrp pathway of Pseudomonas solanacearum. EMBO J. 13:543-553.

Béclin, C., Charlot, F., Botton, E., Jouanin, L., and Doré, C. 1993. Potential use of the aux2 gene from Agrobacterium rhizogenes as a conditional negative marker in transgenic cabbage. Transgenic Res. 2:48-55.

Bertolla, F., Van Gijsegem, F., Nesme, X., and Simonet, P. 1997. Conditions for natural transformation of Ralstonia solanacearum. Appl. Environ. Microbiol. 63:4965-4968.

Boucher, C. A., Barberis, P. A., Trigalet, A. P., and Demery, D. A. 1985. Transposon mutagenesis of Pseudomonas solanacearum: Isolation of Tn5 induced avirulent mutants. J. Gen. Microbiol. 131:2449-2457.

Boucher, C. A., Van Gijsegem, F., Barberis, P. A., Arlat, M., and Zischek, C. 1987. Pseudomonas solanacearum genes controlling both pathogenicity on tomato and hypersensitivity on tobacco are clustered. J. Bacteriol. 169:5626-5632.

Brito, B., Marenda, M., Barberis, P., Boucher, C., and Genin, S. 1999. $p r h J$ and $h r p G$, two new components of the plant signal-dependent regulatory cascade controlled by PrhA in Ralstonia solanacearum. Mol. Microbiol. 31: 237-252.

Burns, J. L., and Hedin, L. A. 1991. Genetic transformation of Pseudomonas cepacia using electroporation. J. Microbiol. Methods 13:215-221.

Cook, D. R., and Sequeira, L. 1991. Genetic and biochemical characterization of a gene cluster from Pseudomonas solanacearum required for extracellular polysaccharide production and for virulence. J. Bacteriol. 173:1654-1662.
Denny, T. P., Carney, B. F., and Schell, M. A. 1990. Inactivation of multiple virulence genes reduces the ability of Pseudomonas solanacearum to cause wilt symptoms. Mol. Plant-Microbe Interact. 3:293300.

Gebhard, F., and Smalla, K. 1998. Transformation of Acinetobacter sp. BD413 by transgenic sugar beet DNA. Appl. Environ. Microbiol. 64: 1550-155.

Hayward, A. C. 1991. Biology and epidemiology of bacterial wilt caused by Pseudomonas solanacearum. Annu. Rev. Phytopathol. 29: 65-87.

Hayward, A. C., and Hartman, G. L. 1994. Bacterial wilt: The disease and its causative agent, Pseudomonas solanacearum. CAB Int., Wallingford, UK.

Lorenz, M. G., and Wackernagel, W. 1992. Stimulation of natural genetic transformation of Pseudomonas stutzeri in extracts of various soils by nitrogen or phosphorus limitation and influence of temperature and $\mathrm{pH}$. Microb. Releases 1:173-176.

Lorenz, M. G., and Wackernagel, W. 1994. Bacterial gene transfer by natural transformation in the environment. Microbiol. Rev. 58:563602.

Manceau, C., Gardan, L., and Devaux, M. 1986. Dynamics of RP4 plasmid transfer between Xanthomonas campestris pv. corylina and Erwinia herbicola in hazelnut tissues, in planta. Can. J. Microbiol. 32: 835-841.

Maniatis, T. A., Fritsch, E. F., and Sambrook, J. 1982. Molecular Cloning: A Laboratory Manual. Cold Spring Harbor Laboratory, Cold Spring Harbor, NY.

Maynard Smith, J., Dowson, C. D., and Spratt, B. G. 1991. Localized sex in bacteria. Nature 349:29-31.

Maynard Smith, J., Smith, N. H., O'Rourke, M., and Spratt, B. G. 1993. How clonal are bacteria. Proc. Natl. Acad. Sci. USA 90:4384-4388.

Message, B., Boistard, P., Pitrat, M., Smith, J., and Boucher, C. 1978. A new class of fluidal avirulent mutant of Pseudomonas solanacearum unable to induce a hyper sensitive reaction. Pages 823-833 in: Proc. Int. Conf. Pathogenic Bacteria, Angers, 4th ed. INRA, Angers, France.

Normand, P., Orso, S., Cournoyer, B., Jeannin, P., Chapelon, C., Dawson, J., Evtushenko, L., and Misra, A. 1996. Molecular phylogeny of the genus Frankia and related genera and emendation of the family Frankiaceae. Int. J. Syst. Bacteriol. 46:1-9.

Paget, E., Jocteur Monrozier, L., and Simonet, P. 1992. Adsorption of DNA on clay minerals: Protection against DNaseI and influence on gene transfer. FEMS Microbiol. Lett. 97:31-40.

Prentki, P., and Krisch, H. M. 1984. In vitro insertional mutagenesis with a selectable DNA fragment. Gene 29:303-313.

Prior, P., Steva, H., and Cadet, P. 1990. Aggressiveness of strains of Pseudomonas solanacearum from the French West Indies (Martinique and Guadeloupe) on tomato. Plant Dis. 74:962-965.

Roberts, D. P., Denny, T. P., and Schell, M. 1988. Cloning of the egl gene of Pseudomonas solanacearum and analysis of its role in phytopathogenicity. J. Bacteriol. 170:1445-1451.

Roszak, D. B., and Colwell, R. R. 1987. Survival strategies of bacteria in the natural environment. Microbiol. Rev. 51:365-379.

Schlüter, K., Fütterer, J., and Potrykus, I. 1995. Horizontal gene transfer from a transgenic potato line to a bacterial pathogen (Erwinia chrysanthemi) occurs if at all at an extremely low frequency. Bio/Technology 13:1094-1098.

Simon, R., Priefer, U., and Pühler, A. 1983. Vector plasmids for in vivo and in vitro manipulations of Gram negative bacteria. Pages 98-105 in: Molecular Genetics of Bacterial-Plant Interactions. A. Pühler, ed. Springer Verlag. Berlin.

Simonet, P., Normand, P., Moiroud, A., and Bardin, R. 1990. Identification of Frankia strains in nodules by hybridization of polymerase chain reaction products with strain specific oligonucleotide probes. Arch. Microbiol. 153:235-240.

Smith, M. W., Feng, D. F., and Doolittle, R. F. 1992. Evolution by acquisition: The case of horizontal gene transfers. Trends Biochem. Sci. $17: 489-493$.

Vasse, J., Frey, P., and Trigalet, A. 1995. Microscopies studies of intercellular infection and protoxylem invasion of tomato roots by Pseudomonas solanacearum. Mol. Plant-Microbe Interact. 8:241-251. 